\title{
The Future Contribution of Demand Side Management to Solving Kenya's Energy Insecurity Problems
}

\author{
E. Kiprop, K. Matsui, and N. Maundu
}

\begin{abstract}
With technological advancement, demand side management has become important part of energy conservation in developed countries. In developing countries, it can also contribute to alleviating energy supply insecurity, but so far only a few countries have adopted it. This paper attempts to understand how administrative personnel in Kenya's government agencies, including energy research institutions, perceived about the acceptability and accessibility of demand side management among the electricity consumers. We conducted the questionnaire survey among government officials, independent power producers and researchers to identify their perceptions about public awareness, willingness, and practice of adopting demand side management. Our questionnaire also attempted to clarify the viability and the impact of implementing various demand side management options. The results show that about $68 \%$ of the respondents believed that the public had low awareness. About $62 \%$ were still optimistic that the electricity consumers would adopt demand side management in the future. In terms of educating the consumers about the importance of this management, about $72 \%$ were rarely engaged. As to the extent to which our respondents found the viability of various demand side management options, the respondent emphasized the importance of price-responsive demand $(81 \%)$, renewable energy adoption by households (74\%), energy efficiency and conservation (64\%) and integration of smart appliances (61\%). About $48 \%$ of the respondents believed that the peak demand would be reduced by over $50 \%$ by implementing these options.
\end{abstract}

Index Terms-Demand side management, Kenya's energy sector, electricity consumers, energy experts.

\section{INTRODUCTION}

Past studies [1]-[3] have proposed ideas to solve energy insecurity that many developing countries have faced. These ideas range from energy generation capacity/storage improvement to demand side management. All these appear to have both positive and negative implications. Building new power plants, for example, can increase energy generation capacity but raise concerns about environmental issues. Large-scale storage technologies are still at development stages. Pumped hydro storage, despite its a mature large-scale technology, has geographical limitations [3].

Manuscript submitted on August 25, 2019; revised January 3, 2020.

E. Kiprop is with the Graduate School of Life and Environmental Sciences, University of Tsukuba, Tsukuba 305-8572, Japan (e-mail: kipropkengu@gmail.com).

K. Matsui is with the Faculty of Life and Environmental Sciences, University of Tsukuba, Tsukuba 305-8572, Japan (e-mail: kenichim@envr.tsukuba.ac.jp).

N. Maundu is with the Ministry of Energy and Petroleum, Nairobi 30582-00100, Kenya (e-mail: nickmaundu2014@gmail.com).
Demand side management implies demand-side technologies, actions and programs that can reduce energy consumption and contribute to GHG emission reduction [4]. Previous researches on demand side management [1], [2], [4]-[6] emphasized its effectiveness in managing electricity consumption. Walawalkar [7] showed that demand side management could also be useful in solving energy challenges associated with the expected widespread adoption of intermittent renewable energy sources. On the other hand, Davito [1] noted that in the past demand side management had limited available technologies. Therefore, it focused only on industrial and commercial consumers while neglecting residential ones. However, the availability of smart grid and smart meters have recently allowed all consumers, including residential ones, to be involved. The US Federal Energy Regulatory Commission estimated that demand side management could potentially reduce as much as $150 \mathrm{GW}$ in the 2019 peak energy period, compared to the business-as-usual scenario. As typical peaking power plant produces about $75 \mathrm{MW}$, this reduction is equivalent to the output of about 2,000 such power plants [8]. A similar study in the UK estimated that a potential reduction of 1.2-4.4 GW was achievable with existing demand side management options in the non-domestic sectors. Additionally, the UK Department of Trade and Industry (DTI) estimated that residents and small businesses can save up to $1 \mathrm{GW}$ through demand management [9].

Despite these promising outcomes, Muratori [4]concluded that a local optimum solution of demand side management may not lead to global optimum. Therefore, a country specific research is needed to optimize the benefits of this method for each location. In addition, developing countries have not paid much attention to demand side management. In Kenya, for example, the government focuses on increasing generation capacity and interconnecting its grid with other Eastern Africa Power Pool (EAPP) countries [10]. These strategies have resulted in higher supply than demand capacity. For example, the 2018 peak demand was $75 \%$ of the installed capacity and that of 2021 was projected to be $43 \%$ [11], [12]. Although the installed capacity exceeds the peak demand, the country still experiences frequent power outages.

This paper argues that demand side management is one of the most viable options to alleviate power outages in Kenya. This, in turn, will contribute to Kenya's goal of supplying $100 \%$ energy from renewable sources. In this paper, we seek to address the following questions: how do government officials understand about the electricity consumer acceptance of this management? What are the most viable demand side management options for Kenya? Our previous 
study [9] on demand side management in Kenya focused on household energy consumers' perceptions. However, this paper examines perceptions of policymakers and implementers in Kenya to better identify challenges to formulating and implementing demand side management programs.

\section{MAterials AND METHODS}

\section{A. Data Collection}

As this study targeted energy policy formulation and implementation, we administered questionnaire to technical personnel at the Ministry of Energy and Petroleum, government agencies (Kenya Power and Lighting Company, Energy and Petroleum Regulatory Authority, Rural Electrification and Renewable Energy Corporation, Geothermal Development Corporation, Kenya Electricity Transmission Company, Ltd.), independent power producers, and academic institutions.

The methodologies of most [13]-[15] of the previous studies on demand side management have been based on modelling and simulation. Apart from being expensive, these methodologies does not put into consideration the human factors that are the main determinants of demand side management adoption by consumers. On the other hand, this study utilizes energy experts' first-hand experience and clear understanding of Kenya's energy sector. In addition, from their understanding of Kenyan electricity consumers, they can give a better prediction of their behavior if given an opportunity to adopt demand side management practices.

The questionnaire survey was administered between May and July 2019. Prior to this, a preliminary survey was conducted to make sure that the respondents could understand all the questions. The questionnaire was then administered to 31 personnel through purposive sampling.

The design of our questionnaire was formulated after reviewing studies on demand side management [1], [7]-[9], [16], [17], consumer perception and awareness on demand side management [2], [4], [18], [19], demand side management adoption [20]-[22], and peak demand reduction [14], [15], [23], [24]. In addition, we carried out an extensive review of government publications on Kenya's energy sector [10]-[12], [25].

The questionnaire was divided into five sections. The first section identified the socio-demographic characteristics of the respondents. The second section looked into the respondents' perceptions about public awareness and willingness to adopt demand side management. The third section investigated current demand side management practices. In the fourth section, we sought to understand the viability of various demand side management practices in Kenya. The fifth section investigated the extent to which the current peak demand would be reduced with demand side management implementation. The collected data were coded and entered into Microsoft Excel 2016. The data were analyzed by using Microsoft Excel Analysis ToolPak and summarized using both descriptive and inferential statistics.

\section{RESULTS AND DISCUSSION}

\section{A. Socio-Demographic Characteristics}

The first part of the questionnaire on socio-demographic characteristics identified age, gender, organization, work experience and educational level of the respondents. About $87 \%$ of the respondents were males. Regarding age, about $71 \%$ fell within an age bracket of 30-39 years old. The section on education qualification showed that only $3 \%$ of the respondents had diploma (middle level college) while about $55 \%$ had postgraduate degrees. About $58 \%$ of the respondents had 5 to 10 years of work experience and about $19 \%$ had more than 10 years. The respondents worked for government energy agencies (45\%), the Ministry of Energy and Petroleum (39\%). Others include, independent power producers (10\%) and academic institutions (6\%).

\section{B. Level of Awareness and Willingness to Adopt Demand Side Management Practices}

In the second section of the questionnaire, we asked their perceptions about public awareness of and willingness to adopt demand side management. First, we asked them to rate the level of consumers' awareness of the importance and availability of demand side management. We then asked them to rate consumers' willingness to adopt demand side management programs.

Regarding the level of awareness, about $68 \%$ of the respondents rated consumers' awareness as low or very low, $13 \%$ as average and $19 \%$ as high (Fig. 1). The low level of awareness could be attributable to the lack of consumer education and sensitization. Previous researches [6], [21] showed that awareness and knowledge precedes the adoption of demand side management.

Our multiple regression analysis found that organization $(p$-value $=5.01 \mathrm{E}-05)$, experience $(p$-value $=7.951 \mathrm{E}-03)$ and education ( $p$-value $=2.934 \mathrm{E}-02)$ significantly affected their perceptions about awareness of demand side management. Further analysis showed that most of the respondents at the Ministry of Energy and Petroleum (83\%) tended to find public awareness low or very low. In addition, those respondents with 5 to 10 years $(78 \%)$ of work experience rated likewise. On the contrary, all those respondents at academic institutions regarded the public awareness as high or very high. This shows a perception gap between academics and government officials.

On the second question, about $62 \%$ of the respondents rated consumers' willingness to adopt demand side management as very high or high, $19 \%$ as average, and $20 \%$ as low or very low. The reason for the high level of willingness to adopt demand side management could be attributable to the high utility cost Kenyan consumers' experience. Similarly, consumers in other countries [19], [26], [27] indicated that they would like to adopt demand side management for cost saving.

Our multiple regression analysis showed that respondents' age $\quad(p$-value $=4.510 \mathrm{E}-05), \quad$ gender $\quad(p$-value $=2.016 \mathrm{E}-04)$, experience $\quad(p$-value $=1.021 \mathrm{E}-02) \quad$ and education ( $p$-value $=1.837 \mathrm{E}-04)$ significantly affected their perceptions about willingness. Further analysis showed that those who rated the willingness as high or very high tended to be 
between 20 and 29 years old $(75 \%)$. All female respondents and most of those with less than 5 years of experience $(72 \%)$ responded likewise.

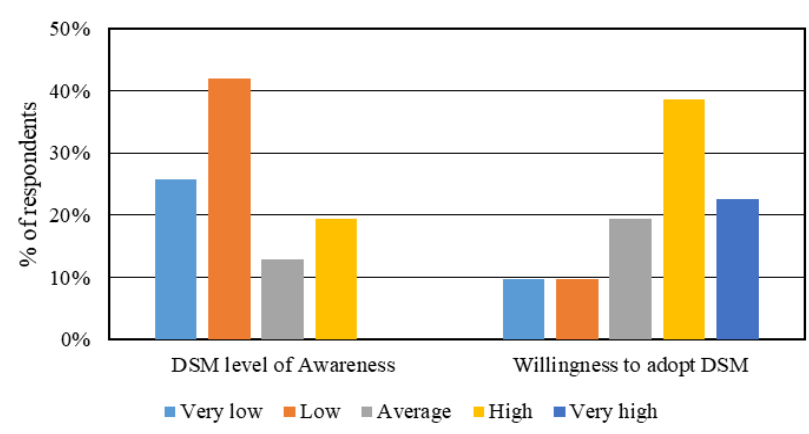

Fig. 1. Level of awareness and willingness to adopt demand side management (DSM) programs.

\section{Education and Practices on Demand Side Management}

In the third section of the questionnaire, we first asked the respondents how often consumers received education on demand side management by their respective organizations. We then asked them to what extent the consumers currently practiced demand side management.

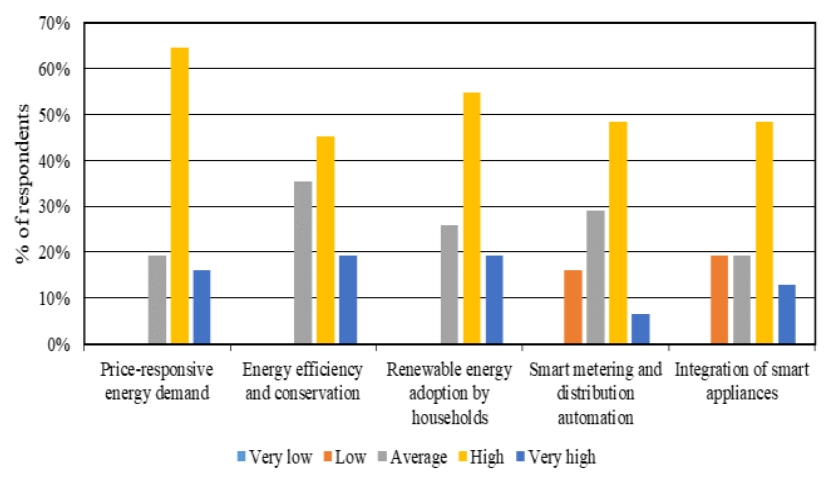

Fig. 2. Viable demand side management practices in Kenya.

Concerning the first question, about $72 \%$ of the respondents indicated that they rarely educated consumers while the rest indicated that they educated quarterly. Similar studies in the US, Korea and other countries [1], [13], [21], [26], [27] emphasized the importance of consumer education.

Our regression analysis indicated that age $(p$-value $=5.359 \mathrm{E}-03), \quad$ organization $\quad(p$-value $=4.866 \mathrm{E}-05)$, experience $\quad(p$-value $=5.77 \mathrm{E}-03)$ and education $(p$-value $=1.011 \mathrm{E}-04)$ affected their perceptions about information dissemination. Those who rarely informed consumers belonged to age groups of 30-39 years old (77\%). They were also working for academic institutions. Those with 5-10 years of experience (89\%) and those with bachelor's degree (77\%) fit into this category. This suggests that consumer education is done mainly by the Kenya Power and Lighting Company or the Ministry of Energy and Petroleum.

As for the second question, about $29 \%$ of the respondents considered consumers to practice demand side management sometimes, about $35 \%$ rarely, $19 \%$ not at all. Presently only a small number of consumers have installed smart meters while those in the rural areas have installed solar PV as a way of reducing their power demand [28]. Previous researches from other countries [20]-[22] attributed the low adoption rates of demand side management to the lack of infrastructure and the skepticism among electricity consumers.

Our regression analysis indicated that age $(p$-value $=2.316 \mathrm{E}-03), \quad$ gender $(p$-value $=1.012 \mathrm{E}-03), \quad$ and experience $(p$-value $=1.343 \mathrm{E}-02)$ affected their perceptions on consumers' current practices. All the respondents above 40 years old and all the female believed that the public rarely use demand side management. Those with more than 10 years of work experience also indicated so.

\section{The Viability of Various Demand Side Management Practices}

In the fourth section, we sought to find out the viability of various demand side management options. We asked the respondents to rate the viability of these options. The results showed that price-responsive demand $(81 \%)$, renewable energy adoption by households (74\%), energy efficiency and conservation $(64 \%)$, and integration of smart appliances $(61 \%)$ were the most viable (Fig. 2). Smart meters and distribution automation (54\%) ranked the lowest.

Basically, the purpose of price-responsive energy demand is to entice consumers to shift their power demand to a time period when the generation cost is lower [9]. This corresponds with findings of some previous researches in the US and Europe [1], [29]. In the US, for example, a peak demand reduction of $5 \%$ could reduce the demand for peaking generation by $50 \%$ [30]. In Kenya, the peak demand is about $12 \%$ of installed capacity [9], [11]. This demand capacity can be reduced significantly if consumers monitor real time prices and shift their demand to off peak hours.

Our regression analysis found the notable connection between the responses on price-responsive energy demand with gender $(p$-value $=1.807 \mathrm{E}-03)$ and education ( $p$-value $=3.559 \mathrm{E}-02)$. Most of the male respondents $(89 \%)$ and those with postgraduate degree $(95 \%)$ tended to rate high or very high.

About $74 \%$ of the respondents found household renewable energy adoption viable as Kenya has a high potential for solar PV generation [31]. As the household sector is the fastest growing energy consumer base, the cost of solar PV and small-scale storage has been significantly reduced [9]. A previous survey on Kenya's electricity consumers indicated that $84 \%$ wanted to adopt renewable energy sources [28]. Here our regression analysis found significant connection between the viability of household renewable energy adoption and respondents' age (p-value=2.346E-03), education $\quad(\mathrm{p}$-value $=3.080 \mathrm{E}-06) \quad$ and experience ( $p$-value $=4.471 \mathrm{E}-04)$. Those who responded high or very high were within the age bracket of 30-39 years old (69\%). Also, most of those with bachelor's degree (85\%) and those with more than 10 years of work experience $(83 \%)$ fell into this category.

Another highly viable option the respondents selected was energy efficiency and conservation. Kenya has recently improved energy efficiency. For instance, in 2009 and 2012, the government, implemented the first and second phases respectively of efficient lighting programs for residential areas, distributing 4.8 million compact fluorescent lamps (CFLs). The programs resulted into a peak demand reduction 
of $178 \mathrm{MW}$ (11\% of 2012 installed capacity) [9].

Here our multiple regression analysis found the significant connection between energy efficiency/conservation and respondents' gender ( $p$-value $=2.353 \mathrm{E}-02)$ and education $(p$-value $=2.470 \mathrm{E}-02)$. The majority of male respondents $(74 \%)$ and those with postgraduate degrees $(95 \%)$ indicated high or very high.

As for the integration of smart appliances, although the respondents found important, our multiple regression analysis showed no significant relationship between the viability of integrating smart appliances and the respondents' socio-demographic characteristics.

Although smart metering and distribution automation ranked the lowest, our multiple regression analysis found the significant connection between this option and respondents' organization $(p$-value=1.683E-02). Kenya has started installing smart meters and adopting grid modernization [10], [12].

\section{E. Impact of Demand Side Management Implementation on Peak Demand}

In the fifth section, we investigated the extent to which the current peak demand would be reduced with demand side management. We asked the respondents about the extent to which the peak demand would be reduced by demand side management implementation.

In response, about $48 \%$ of the respondents indicated that the peak demand would be reduced by more than $50 \%$. Another $23 \%$ said that it would be reduced by 40 to $49 \%$ (Fig. 3). This result corresponds with the findings of the studies in the US, Italy, and UK [1], [14], [15], [23], [24].

Here our multiple regression analysis found the significant connection between the impact of demand side management implementation and respondents' age ( $p$-value $=2.942 \mathrm{E}-05)$, gender $(p$-value $=1.86 \mathrm{E}-05)$, experience $(p$-value $=4.848 \mathrm{E}-04)$ and education ( $p$-value $=5.85 \mathrm{E}-08)$. Those who were 20 to 39 years old $(76 \%)$ and female $(75 \%)$ respondents tended to believe the reduction rate to be more than $40 \%$. Those with postgraduate degrees $(84 \%)$ and with less than 10 years of work experience $(78 \%)$ indicated the same.

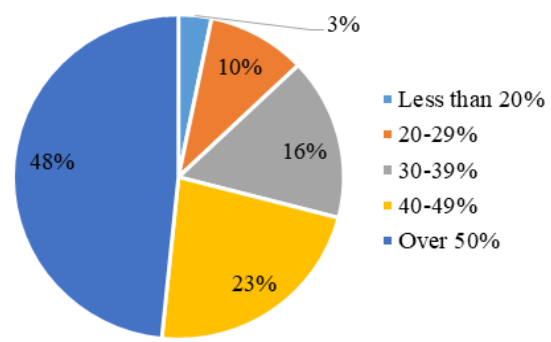

Fig. 3. The impact of full demand side management implementation on peak demand.

\section{CONCLUSION}

This paper examined perceptions of policymakers and implementers about Kenya's electricity consumers' awareness, willingness, and practices concerning demand side energy consumption management. We also investigated the viability and the impact of implementing various demand side management practices. We found that about $67 \%$ of the respondents, mostly working for the Ministry of Energy and
Petroleum, considered consumers' awareness level as low. However, about $62 \%$ were hopeful that consumers were willing to adopt demand side management. Our respondents believed that price responsive demand $(81 \%)$, renewable energy adoption by households (74\%), energy efficiency and conservation (64\%) and integration of smart appliances (61\%) were the most viable options in Kenya. Most of the respondents with postgraduate degrees perceived price responsive demand as the most viable option. By implementing some of these demand side management practices, about $48 \%$ of the respondents, mostly with postgraduate degrees, said that the peak demand would be reduced by over $50 \%$. Another salient finding is a gap in opinion between researchers and government officials. Those respondents who worked for research institutions perceived the high level of consumer awareness of demand side management, but those at government ministries perceived otherwise. While this paper showed that the Kenyan consumers' willingness to adopt demand side management is high, the determination that this would translate to actual high adoption rate is beyond the scope of the current research.

\section{CONFLICT OF INTEREST}

"The authors declare no conflict of interest".

\section{AUTHOR CONTRIBUTIONS}

Conceptualization, design of questionnaire, visualization, methodology, formal data analysis, writing - original draft preparation, E. Kiprop; questionnaire review and revision, writing-review, revision and editing, supervision, project administration, K. Matsui; data collection, writing - review and editing, N. Maundu. E. Kiprop served as the corresponding author. All the authors read and approved the final manuscript.

\section{REFERENCES}

[1] B. Davito et al., "The smart grid and the promise of demand-side management," McKinsey on Smart Grid, pp. 8-44, 2010.

[2] M. Goulden, B. Bedwell, S. Rennick-Egglestone, T. Rodden, and A. Spence, "Energy research \& social science smart grids, smart users? The role of the user in demand side management," Energy Res. Soc. Sci., vol. 2, pp. 21-29, 2014.

[3] P. Warren, "A review of demand-side management policy in the UK," Renew. Sustain. Energy Rev., vol. 29, pp. 941-951, 2014.

[4] M. Muratori, B. Schuelke-leech, and G. Rizzoni, "Role of residential demand response in modern electricity markets," Renew. Sustain. Energy Rev., vol. 33, pp. 546-553, 2014.

[5] D. N. Mah, J. M. Vleuten, P. Hills, and J. Tao, "Consumer perceptions of smart grid development: Results of a Hong Kong survey and policy implications," Energy Policy, vol. 49, pp. 204-216, 2012.

[6] M. C. Claudy, C. Michelsen, A. O. Driscoll, and M. R. Mullen, "Consumer awareness in the adoption of microgeneration technologies An empirical investigation in the Republic of Ireland," vol. 14, pp. 2154-2160, 2010.

[7] R. Walawalkar, S. Fernands, N. Thakur, and K. Reddy, "Evolution and current status of demand response ( DR ) in electricity markets: Insights from PJM and NYISO," Energy, vol. 35, no. 4, pp. 1553-1560, 2010 .

[8] Federal Energy Regulatory Commission, A National Assessment of Demand Response Potential, June, 2009

[9] E. Kiprop, K. Matsui, J.M. Karanja, H. Andole, and N. Maundu, "Demand side management opportunities in meeting energy demand in Kenya," Grand Renewable Energy proceedings Japan Council for Renewable Energy, 2018, p. 18. 
[10] Energy Regulatory Commission, "Least cost power development plan 2017-2037," Nairobi Kenya, 2018.

[11] Kenya Power, "Monthly report to the Ministry of Energy on the power supply situation and progress in implementation of priority projects coordinated by KPLC," Nairobi Kenya, August, 2018.

[12] Kenya Power and Lighting Company, "Grid development and maintenance plan," Nairobi, 2016.

[13] C. Park, H. Kim, and Y. Kim, "A study of factors enhancing smart grid consumer engagement," Energy Policy, vol. 72, pp. 211-218, 2014.

[14] C. Su and D. Kirschen, "Quantifying the effect of demand response on electricity markets," 2009.

[15] P. Siano, "Demand response and smart grids - A survey," Renew. Sustain. Energy Rev., vol. 30, pp. 461-478, 2014.

[16] D. T. Nguyen, "Demand response eXchange in a deregulated environment," Ph.D. Thesis, Department of Engineering, University of Tasmania, 2012.

[17] B. Shen, G. Ghatikar, Z. Lei, J. Li, G. Wikler, and P. Martin, "The role of regulatory reforms, market changes, and technology development to make demand response a viable resource in meeting energy challenges," Appl. Energy, vol. 130, pp. 814-823, 2014.

[18] D. Mah, J. M. Vleuten, J. C. Ip, and P. Hills, "Governing the transition of socio-technical systems: A case study of the development of smart grids in Korea," Green Energy Technol., vol. 45, no. 9781447162803, pp. 259-277, 2014.

[19] N. Balta-Ozkan, O. Amerighi, and B. Boteler, "A comparison of consumer perceptions towards smart homes in the UK, Germany and Italy: reflections for policy and future research," Technol. Anal. Strateg. Manag., vol. 26, no. 10, pp. 1176-1195, 2014.

[20] O. Ellabban and H. Abu-Rub, "Smart grid customers' acceptance and engagement: An overview," Renew. Sustain. Energy Rev., vol. 65, pp. 1285-1298, 2016.

[21] A. Kowalska-Pyzalska, "What makes consumers adopt to innovative energy services in the energy market? A review of incentives and barriers," Renew. Sustain. Energy Rev., vol. 82, no. October 2017, pp. 3570-3581, 2018.

[22] N. D. Sintov and P. W. Schultz, "Unlocking the potential of smart grid technologies with behavioral science," vol. 6, no. April, pp. 1-8, 2015.

[23] G. Dm et al., "Methods and applications for electricity demand disaggregation in developing countries models," July, 2016.

[24] N. G. Paterakis, O. Erdinç, and J. P. S. Catalão, "An overview of demand response : Key-elements and international experience," Renew. Sustain. Energy Rev., vol. 69, no. November 2016, pp. 871-891, 2017.

[25] Government of the Republic of Kenya, " $5000+$ MW by 2016: Power to transform Kenya," Nairobi, 2013.

[26] T. Hargreaves, M. Nye, and J. Burgess, "Making energy visible: A qualitative field study of how householders interact with feedback from smart energy monitors," Energy Policy, vol. 38, no. 10, pp. 6111-6119, 2010.

[27] H. Allcott, "Social norms and energy conservation," J. Public Econ., vol. 95, no. 9-10, pp. 1082-1095, 2011.

[28] E. Kiprop, K. Matsui, and N. Maundu, "Can Kenya supply energy with $100 \%$ renewable sources?" in Proc. Internaional Conference on Environment and Renewable Energy,pp. 50-55, 2017.

[29] J. Märkle-huß, S. Feuerriegel, and D. Neumann, "Large-scale demand response and its implications for spot prices, load and policies : Insights from the German-Austrian electricity market," Appl. Energy, vol. 210, pp. 1290-1298, 2018

[30] K. Spees and L. B. Lave, "Impacts of responsive load in PJM: Load shifting and real time pricing," Energy Journal, vol. 29, no. 2, 2008.

[31] E. Kiprop, K. Matsui, and N. Maundu, "The role of household consumers in adopting renewable energy technologies in Kenya," Environments, 2019.

Copyright $(2020$ by the authors. This is an open access article distributed under the Creative Commons Attribution License which permits unrestricted use, distribution, and reproduction in any medium, provided the original work is properly cited (CC BY 4.0).

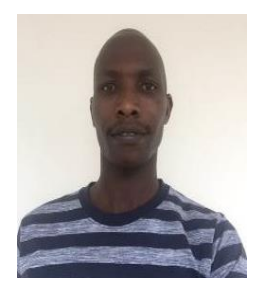

Eliud Kiprop was born in Eldoret-Kenya on $28^{\text {th }}$ August, 1987. Currently, he is a PhD student at the Graduate School of Life and Environmental Sciences, the University of Tsukuba, Tsukuba-Japan. He received a master of engineering in 2017 from the Ashikaga Institute of Technology, Ashikaga-Japan and the bachelor of engineering in chemical and process in 2011 from Moi University, Eldoret-Kenya. He was an intern at the Lami Corporation in Osaka and OPC Corporation in Tokyo (2017). He has also worked as an assistant factory manager at Eastern Produce Kenya Limited (Chemomi Tea Factory) from 2013 to 2014. Some of his publications include: 1) Eliud Kiprop, Kenichi Matsui, and Nicholas Maundu, The Role of Household Consumers in Adopting Renewable Energy Technologies in Kenya, Environments, Vol.6 No. 82019 2) Kiprop Eliud, Nicholas M. Maundu, Dickson Kindole, Alfred Mukama, Sam K. Kosgei, Yasuyuki Nemoto, Yuichi Nakajo; Study of Performance Characteristics of Small Submersible Pump Run as Hydro Turbine Generator, Sustainable Energy, Vol.5, No.1.1-5. 2017, 3) Nicholas Musembi Maundu, Kosgei Sam Kiptoo, Yuichi Nakajo, Kiprop Eliud and Dickson Kindole; Air-flow Distribution Study and Performance Analysis of a Natural Convection Solar Dryer, American Journal of Energy Research. Vol.5, No.1, 12-22, 2017. His research interests include demand side management, smart grid, and assessment of renewable energy resource potential. He has investigated how countries like Kenya can reliably meet power demand with $100 \%$ renewable energy sources.

Mr. Kiprop is a member of Engineers Board of Kenya. Between 2015 and 2017, he was a member of the Japan Solar Energy Society (JSES).

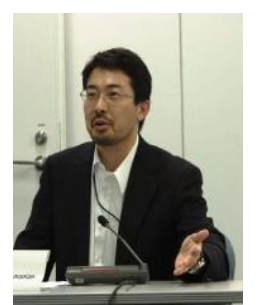

Kenichi Matsui received the MA from Arizona State University, the U.S. in 1996, and the PhD from the University of British Colombia, Canada in 2003. He is associate professor of the Faculty of Life and Environmental Sciences at the University of Tsukuba, Japan. There he is a chair of the Sustainability, Science, Technology and Policy (SUSTEP) Program. He has published several books and numerous articles about water law/ethics, environmental policy, environmental history, agricultural policies, indigenous studies, and environmental dispute resolutions.

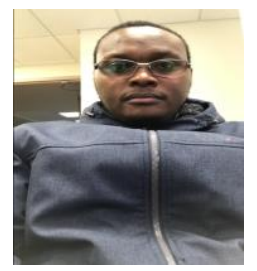

Nicholas M. Maundu was born in Nairobi-Kenya on $28^{\text {th }}$ October, 1983 . He graduated from the University of Nairobi, Nairobi-Kenya with a bachelor degree in electrical and electronics engineering (2009) and has a master's degree in engineering from Ashikaga Institute of Technology, Ashikaga-Japan (2017). He has worked with M\&E, Nairobi (2009) as well as Gedox Associates, Nairobi $(2009,2010)$ as a consulting graduate electrical engineer in Kenya. He joined the Ministry of Energy, Nairobi Headquarters-Kenya in July, 2010 as electrical engineer-II where he has grown through the job ranks to the current position of a principal renewable energy officer in the same ministry. Some of his previous researches include; 1) Nicholas Musembi Maundu, Kosgei Sam Kiptoo, Yuichi Nakajo; Design and Analysis of Solar Dryer for Mid-Latitude Region, Elsevier, Energy Procedia Vol.100, November 2016, Pages 98-110. 2) Nicholas Musembi Maundu, Kosgei Sam Kiptoo, Yuichi Nakajo, Kiprop Eliud and Dickson Kindole; Air-flow Distribution Study and Performance Analysis of a Natural Convection Solar Dryer, American Journal of Energy Research. 2017. Vol.5, No.1, 12-22. 3) Kiprop Eliud, Nicholas M. Maundu, Dickson Kindole, Alfred Mukama, Sam K. Kosgei, Yasuyuki Nemoto, Yuichi Nakajo; Study of Performance Characteristics of Small Submersible Pump Run as Hydro Turbine Generator, Sustainable Energy, 201, Vol.5, No.1.1-5. His current research interest is on the potential and the future of renewable energy resources in fostering sustainable economic growth.

Mr. Maundu is a registered certified energy manager (Association of Energy Engineers), a licensed Advanced Solar PV system designer and Installer in Kenya (EPRA) and a member of Engineers Board of Kenya. 